\title{
A Support to Neuromotor Rehabilitation based on Multimedia Enhanced Hypnosis
}

\author{
Silvana Cagiada, \\ Association for the Study, \\ Research and Care of \\ the Human Being \\ via IV Novembre 119 \\ 26013 Crema CR Italy
}

\author{
Luigi Canidio \\ Association for the Study, \\ Research and Care of \\ the Human Being \\ via IV Novembre 119 \\ 26013 Crema CR Italy
}

\author{
Rita Pizzi \\ Department of \\ Computer Science \\ University of Milan \\ via Bramante 65 \\ 26013 Crema CR Italy
}

\begin{abstract}
The proposed work stems from positive tests obtained in the past using hypnosis enhanced by multimedia technology as a learning support for people with cognitive disabilities. The present study intends to test the effectiveness of this technique in patients underlying rehabilitation after cerebral ischemic stroke.

Reference is made in this case to the recent discoveries about the function of mirror neurons, whose activation may promote the brain activity necessary for rehabilitation by means of neural circuits usually not used.

For this purpose a software has been developed that provides for two phases: in the first phase the hypnotic induction is realized through the use of colors, music and the voice of the therapist. In the second phase, once induced hypnosis, a series of movements prepared by a physiotherapist of the rehabilitation is displayed on the screen, and the patient is asked to repeat them. Simultaneously, the software also displays images that reproduce movements of the limbs during pleasant and positive aspects of life, in which the subject can identify.

The experiment was conducted at the Hospital of Cream on patients with cerebral ischemic stroke of any etiology (cardioembolic thrombotic, lacunar stroke,), divided into two groups: the first is subjected to traditional rehabilitation, the second was atreated also with multimedia hypnosis. By means of statistical evaluation we have verified that patients undergoing rehabilitation with hypnosis have a significant clinical improvement compared to the control group.
\end{abstract}

\section{Keywords}

Hypnosis, Multimedia, Mirror Neurons, Neuromotor Rehabilitation

\section{INTRODUCTION}

The results of experiments conducted on monkeys in the early 90's by a group of scientists at the University of Parma, led by Giacomo Rizzolatti [1,2,3,4], which had as an objective the understanding of the brain mechanisms involved in recognizing the human behavior, intentions and emotions, have shown that the cerebral motor cortex of the monkey not only serves to control individual muscles to perform movements, but some of its neurons are activated while the monkey executes aimed movements, such as grasping an object. Subsequently, the group has demonstrated that in humans there exists a mirror neurons system.
Actually through the study of functional MRI and PET, positron emission tomography and transcranial magnetic stimulation, in humans activation of the cortical areas of the inferior frontal gyrus and of the inferior parietal lobe has been identified, both during the observation of actions, and during their execution.

Specifically, the observation of the actions of the hand or foot activates those motor areas corresponding to the areas of motor control of the specific effector.

If the same action is performed in the absence of the action objective, namely in the absence of the object, the mirror neurons are not activated.

Some mirror neurons, called audio-visual mirror neurons, work when the sound of an action is listened to, which means that the mirror neuron system is able to activate the motor programs involved in the action within the motor cortex of the listener.

Therefore this mechanism of "internal simulation" uses different sensory channels, the visual and the acoustic ones.

Even in the case of emotions, a mechanism of internal simulation is activated mediated by mirror neurons, and this has shown that we are "neurally" programmed towards an empathic communication between human beings and that these neurons are mainly related to hearing and vision.

The areas of the mirror neuron system are activated automatically by codifying not only the observed motor acts, but also the intentions. Then the observation of a certain behavior activates the premotor cortex, the motor representation of that same action and this information can be used to repeat the same action. Thus a common representational scheme between observed act and perceived act is present, that allows you to directly translate the sensory information into motor acts or in emotional terms.

In fact, the observation of facial expressions related to emotions, such as disgust, activate the same areas that are delegated to the visceromotor reactions linked to that emotion. These studies support the hypothesis that the understanding of emotional states occurs through a mechanism of mirror neurons that automatically translates the sensory experience in emotional terms. The vision of a painful sensation in another person activates the same areas that are involved in the perception of that same feeling.

These studies lead us to know the basic circuits that allow us to understand emotions and intentions of others, as some mental and cognitive processes and empathy, may have as basic mechanism the mirror neurons system [5]. 
In the light of this knowledge, for the purposes of our research on hypnosis in support of rehabilitation, the use of hypnosis could facilitate the relearning of skills that already belong to the motor repertoire of the patient.

When we use hypnosis, we reach the right hemisphere through words, and through the process of hypnosis we establish a simple connection between the left and the right hemisphere $[6,7,8,9]$.

Once this bridge is established, as we know, the hypnotic state can be deepened or directly used: the rational sphere, namely the left hemisphere, processes the data in a logical manner, following experiences and concepts that the subject possesses about reality, as is the case for logic and reasoning; the right hemisphere, instead, processes and stores them in an analog mode, following an assonance of images, sounds and sensations that intersect and merge with each other $[10,11,12]$.

At a therapeutic level a light trance is sufficient, and when there is collaboration, the will helps to cross the bridge between the two hemispheres and to use usually not used circuits.

Through the development of a software that provides the hypnotic induction with the use of music, colors and the therapist's voice, the patient quickly reaches a state of relaxation and well-being that enables him to follow the program with a better "abandonment" by drawing on new reserves of energy.

The vision of a series of movements inherent in a psychomotor rehabilitation program carried out by a physiotherapist, and the simultaneous view of short movies depicting limb movements associated with pleasant moments of everyday life, facilitate patients to such movements that already belong to their motor repertoire.

\section{THE MULTIMEDIA SOFTWARE}

The interactive software is written in Flash and provides that the patient as a first step chooses his/her most pleasant color, that will constitute the basis of the hypnotic induction phase and the background of the following animations.

It is also possible to choose the rehabilitation session suitable for the patient, on the basis of the $\operatorname{limb}(\mathrm{s})$ that must be mobilized.

Once color and kind of rehabilitation have been chosen, the therapist's voice gently guides the patient to the hypnotic induction, supported by an animation based on the stylized image of an iris that gradually changes its colors (Fig. 1).

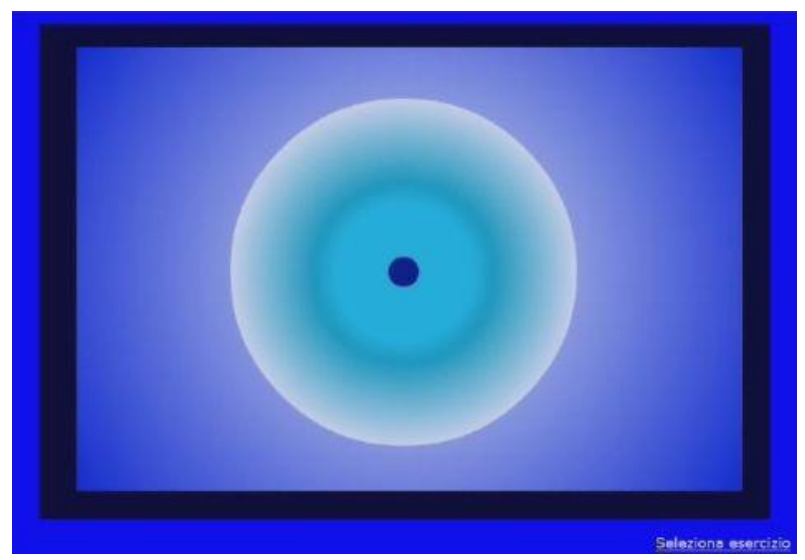

Fig. 1 - The hypnotic induction phase
After a suitable time, the therapist's voice guides the patient, now in a status of light hypnosis, to the rehabilitation phase.

Now the screen combines two different movies: on the left the physiotherapist's movements, that the patient should try to reproduce. On the right side there is a flow of fine motion pictures, where the limb movements are associated to pleasant daily actions: a caress, a breakfast with a dear friend, the hug of the mother with her child, and so on (Fig. 2,3,4).

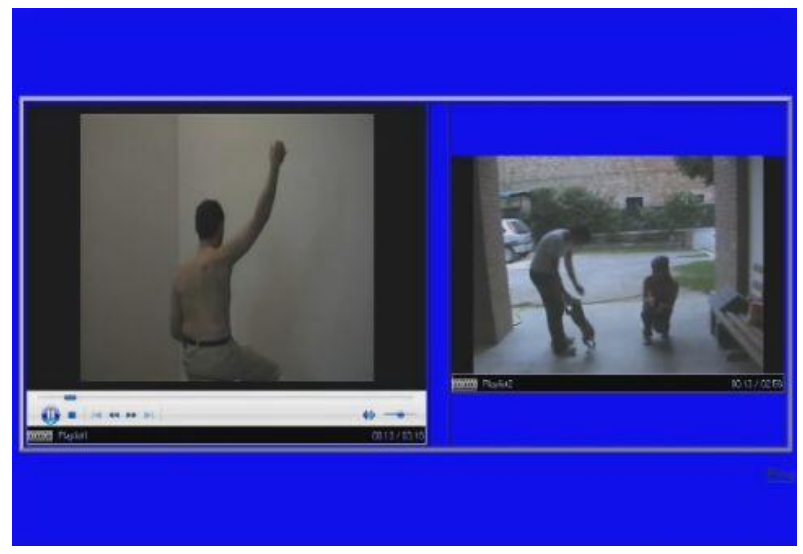

Fig. 2 - Rehabilitation session - screenshot (1)

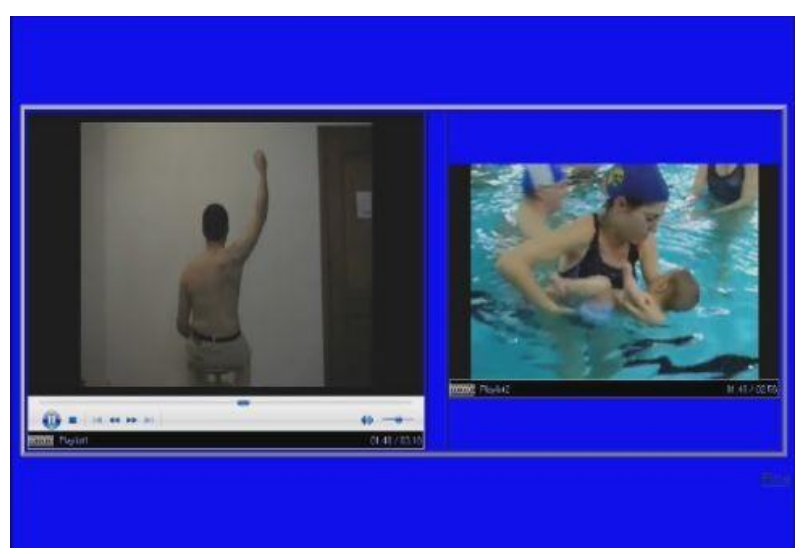

Fig. 3 - Rehabilitation session - screenshot (2)

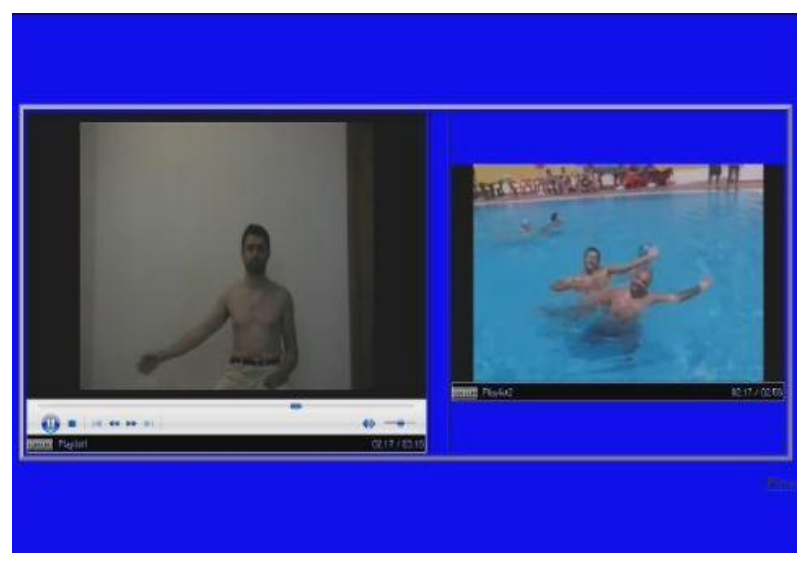

Fig. 4 - Rehabilitation session -screenshot (3) 
All the rehabilitation phase is associated with a calm, relaxing music suitably chisn by the therapist.

At the end of the rehabilitation session, the hypnotic induction session is resumed, while the therapist's voice guides gently the patient back to the normal consciousness condition.

The software is conceived to be executed on a standard multimedia laptop that can be easily placed in the near of the patient, so that she/he can follow the animation phases.

Once the first interactive choices have been taken, the software proceeds autonomously, without any intervention by the patient or the physician, in such a way as not to disturb the hypnotic state.

\section{THE CLINICAL TRIAL}

\subsection{The Previous Experimental Study}

A past study that we carried out with a suitable software hypnosis media had covered 20 subjects with cognitive disability, of which 10 undergoing multimedia hypnosis learning and 10 a classical learning procedure [13]

A learning test was administered the results of which ranged from 0 to 50 .

To establish an outcome measure for the study, we considered to evaluate as positive the results above the $50 \%$ of the available points. We then set the cut-off at 25 points per subject.

The results showed that the average multimedia learning technique in hypnosis allows to widely exceed the cut-off (29 points) while, as expected from the mild cognitive impairment level of the subjects, the score with traditional learning remains low ( 24 points).

\subsection{The New Clinical Trial}

In the light of these positive results, we have undertaken a clinical trial specifically dedicated to the neuromotor rehabilitation. The trial was approved by the Ethics Committee of the Ospedale Maggiore of Crema and carried out at the Neurological and Functional Recovery and Rehabilitation Department.

The multimedia hypnosis software was developed at the Department of Computer Science, University of Milan, Crema Campus.

The criteria for inclusion of patients were as follows:

Patients with cerebral ischemic stroke of any etiology (cardioembolic, thrombotic, lacunar), aged between 35 and 75 years, without dementia or cognitive decline with MMSE> or $=24$ and without severe depression (following the Hamilton scale), absence of severe comorbidities that could affect the ability of motor recovery of the subject.

Were also excluded patients with severe polidistrectual osteoarthritis.

The sample on which the experimentation was carried out included 8 patients: 4 control patients underwent standard rehabilitation, the other 4 patients in rehabilitation standard plus 2 weekly sessions with multimedia hypnosis for 4 weeks (8 sessions).

The 4 patients treated with hypnosis have been motivated to the experiment by means of a psychological interview also upholding their consent.
After the first week after the acute event, patients selected according to the criteria were assessed with MMSE and mode with a score greater than or equal to 24 and Barthel test to evaluate the functional autonomy: these tests are easy to administer and the most commonly used. All 8 patients considered by the trial continued medical treatment and standard physiotherapy until discharge, at which they were evaluated by administering physiatric Barthel test.

At discharge evaluations were carried clinical neurological and physiatric, in particular the Barthel Scale for evaluating the functional autonomy, on which the test was performed for statistical

evaluation

Endpoint of the test was to verify whether patients undergoing rehabilitation with hypnosis for presented a significant clinical improvement compared to the control group. Outcome measure was the statistical evaluation on the Barthel scale using Student's t test for paired data, with a significance level $\mathrm{p}=0.05$.

The results indicate (see Tab. 1) that the average of the differences between Barthel scores before and after the rehabilitation sessions is of 36.25 points for the control group and 60.25 points for the group treated with multimedia hypnosis.

Such a wide difference between means could not but have also reflected at the level of statistical significance. In fact, the results of the Student's t of paired data were as follows:

$\mathrm{P}=0.011742393$ one-tailed Student's $\mathrm{t}$

Table 1. Subjects' Data

\begin{tabular}{|c|c|c|c|}
\hline SUBJECTS & $\begin{array}{c}\text { Barthel } \\
\text { pre-rehab }\end{array}$ & $\begin{array}{c}\text { Barthel } \\
\text { post-rehab }\end{array}$ & Differences \\
\hline Hypno1 & 10 & 47 & 37 \\
\hline Hypno2 & 10 & 67 & 57 \\
\hline Hypno3 & 15 & 100 & 85 \\
\hline Hypno4 & 12 & 74 & 62 \\
\hline mean & 11.75 & 72 & 60.25 \\
\hline sd & 2.36290781 & 21.8936825 & 19.7209702 \\
\hline Control1 & 15 & 35 & 20 \\
\hline Control2 & 10 & 55 & 45 \\
\hline Control3 & $\mathbf{0}$ & 50 & 50 \\
\hline Control4 & 15 & 45 & 30 \\
\hline
\end{tabular}




\begin{tabular}{|c|c|c|c|}
\hline mean & 10 & 46.25 & 36.25 \\
\hline sd & 7.07106781 & 8.53912564 & 13.7689264 \\
\hline
\end{tabular}

The statistical significance request $(\mathrm{P}<0.05)$ is widely verified in both the tests. The one-tailed test nearly reaches $\mathrm{P}$ $=0.01$.

\section{CONCLUSIONS}

The study has allowed us to verify the success of rehabilitation support therapy using multimedia hypnosis technique. In fact, the Barthel score achieved by patients treated with hypnosis media was significantly higher than the score achieved by the control patients.

The hypothesis we began to verify by means of this trial allows us to assume that, thanks to the mirror neurons and with the help of hypnosis enhanced by multimedia technology, it is possible to replicate the movement promoting the relearning, through the activation of new undamaged and usually not used neural circuits.

Although recent works [14,15] show the effectiveness of hypnosis as a support to rehabilitation, they present just case reports and don't include case-control studies with statistical significance. Moreover, to the best of our knowledge, the multimedia approach to hypnosis was never adopted in previous trials.

In the future we aim to reinforce the statistical results with a more numerous recruitment and to improve the multimedia software with a more appealing interface: a suitable choice of images, movies and musics and a complete range of rehabilitation movements. In tis way we aim to obtain better performances based on the deepest involvement of patients and their best collaborative attitude.

\section{ACKNOWLEDGEMENTS}

We hare deeply indebted to Dr. Michele Gennuso, MD, Departments of Neurology of the Crema Hospital and to Dr. Stefano Farina, MD, Department of Functional Rehabilitation of the Crema Hospital, who recruited and attended the patients and yielded all the data necessary to carry out the trial.

\section{REFERENCES}

[1] Rizzolatti G., Craighero L. 2004. The Mirror-Neuron System. Annual Rev. Neurosci. 27 (2004) 169-92.

[2] Rizzolatti G., Fabbri-Destro M., Cattaneo L. 2009. Mirror neurons and their clinical relevance. Nature ClinPract. Neurol 5 (2009) 24-34.
[3] Rizzolatti G., Fadiga L., Gallese V., Fogassi L. 1996. Premotor cortex and the recognition of motor actions. Cogn. Brai n Res., 3 (1996), 131-141.

[4] Rizzolatti G., Fogassi L., Gallese V. 2001. Neurophysiological mechanisms underlying the understanding and imitation of action. Nature Reviews Neuroscience 2 (2001) 661-670.

[5] Balugani R., Ducci G. 2007. Ipnosi e neuroscienze. Neuroni specchio, simulazione ed immaginazione all'opera nell'azione terapeutica. Franco Angeli.

[6] Bandler R., Grinder J. 1984. I Modelli della Tecnica Ipnotica di Milton H. Erickson. Astrolabio.

[7] Erickson M.H. 1978. Le nuove vie dell'ipnosi. Astrolabio.

[8] Shone R. 1982. La tecnica dell'autoipnosi. Astrolabio.

[9] Van der Hart, O. et al. 1993. The treatment of traumatic memories: synthesis realization and integration. Dissociation 6 (1993) 162-180.

[10] Cagiada S., Canidio L., Pennati A. 1997. Successful integrated Hypnotic and Psychopharmacological treatment of a war-related post-traumatic psychological and somatoform dissociative disorder of two years duration (psychogenic coma), Dissociation 10(3) (1997) $182-189$.

[11] Pennati A. 2007. Materiale per una proposta di modello della psicoterapia ipnotica - Part 1: La trance in una prospettiva evoluzionistica. Rivista italiana di Ipnosi e psicoterapia ipnotica .

[12] Canidio L., Cagiada S., Domenichini E. 1992. Il problema della comunicazione nel paziente cosciente ed intubato in rianimazione e terapia intensiva. Atti del II Convegno "Modalità di intervento psicologico in anestesia e rianimazione, Bologna - Rivista Medica Italiana di psicoterapia ed ipnosi 2 (1992) 151-158.

[13] Cagiada S., Canidio L., Pizzi R. 2006. Sperimentazione sull'apprendimento in ipnosi, memorizzazione e ritenzione, rivolta a soggetti che presentano una disabilità medio-lieve, con tecnica multimediale, First Int. Conf. AINP, Lecce 11-12 Nov. 2006. Also in : Rivista di Ipnosi e Psicoterapia Ipnotica (2007) 107-110.

[14] Appel P.R., Clinical hypnosis in rehabilitation 2003. Seminars in Integrative Medicine 1(2) (2003) 90-105.

[15] Diamond S.G., Davis O.C., Schaechter, J.D., Howe, R.D. 2006. Hypnosis for rehabilitation after stroke: Six case studies. Contemporary Hypnosis, 23 (4) (2006) 173-180. 